
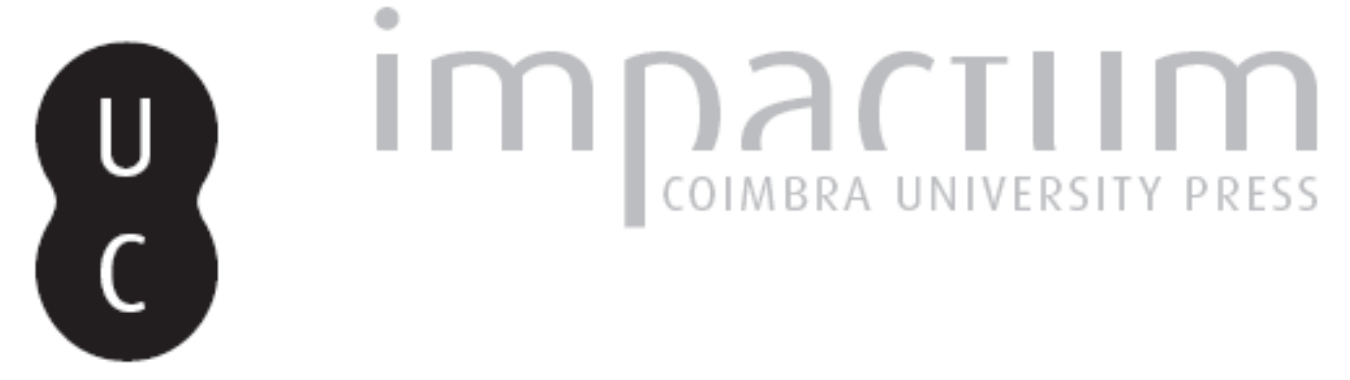

\title{
A perigosidade natural da temperatura do ar em Portugal Continental: a avaliação do risco na mortalidade
}

Autor(es): $\quad$ Marques, Jorge; Antunes, Sílvia

Publicado por: Associação Portuguesa de Riscos, Prevenção e Segurança

URL persistente:

URI:http://hdl.handle.net/10316.2/36144

DOI:

DOI:http://dx.doi.org/10.14195/1647-7723_16_5

Accessed : $\quad$ 26-Apr-2023 08:14:50

A navegação consulta e descarregamento dos títulos inseridos nas Bibliotecas Digitais UC Digitalis, UC Pombalina e UC Impactum, pressupõem a aceitação plena e sem reservas dos Termos e Condições de Uso destas Bibliotecas Digitais, disponíveis em https://digitalis.uc.pt/pt-pt/termos.

Conforme exposto nos referidos Termos e Condições de Uso, o descarregamento de títulos de acesso restrito requer uma licença válida de autorização devendo o utilizador aceder ao(s) documento(s) a partir de um endereço de IP da instituição detentora da supramencionada licença.

Ao utilizador é apenas permitido o descarregamento para uso pessoal, pelo que o emprego do(s) título(s) descarregado(s) para outro fim, designadamente comercial, carece de autorização do respetivo autor ou editor da obra.

Na medida em que todas as obras da UC Digitalis se encontram protegidas pelo Código do Direito de Autor e Direitos Conexos e demais legislação aplicável, toda a cópia, parcial ou total, deste documento, nos casos em que é legalmente admitida, deverá conter ou fazer-se acompanhar por este aviso.

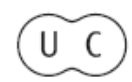




\section{territorium}

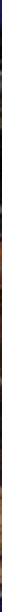

16

Revista da Associação Portuguesa de Riscos, Prevenção e Segurança 2009 


\title{
A PERIGOSIDADE NATURAL DA TEMPERATURA DO AR EM PORTUGAL CONTINENTAL: A AVALIAÇÃO DO RISCO NA MORTALIDADE*
}

\author{
Jorge Marques \\ Instituto de Meteorologia, Lisboa \\ jorge.marquesameteo.pt \\ Silvia Antunes \\ Instituto de Meteorologia, Iisboa \\ silvia.antunesaneteo.pt
}

\begin{abstract}
RESUMO
Neste estudo foram identificadas relações significativas entre a temperatura e a mortalidade (1941-2005) para diversas escalas temporais (ano, estações do ano e meses). As correlaçães detectadas como significativas são positivas no Verão e negativas no Inverno. Os meses destas estaçães do ano são os que influenciam de forma significativa onúmero de abitos em Portugal continental.
\end{abstract}

Palavras chave: Variabilidade climática, mortalidade, temperatura do ar, Portugal continental.

\section{RÉSUMÉ}

Dans celteétude ont été identifiés les relations significatives entre lamortalitéet la température de l'air (19412005) pour les différentes échelles de temps (année, saisons et mois). Les corrélations significatives sont détectées comme positives en été et négatives en hiver. Les mois d'été et d'hiver sont ceux qui influencent le plus le nombre de décès au Portugal.

Mbts-clé: Variabilité clinatique, mortalité, température de l'air, Portugal.

\section{ABSTRACT}

Significant correlations between mortality and air temperature (1941-2005) were identified for several time scales (year, seasons andmonths). The correlations detected as significant are positive in sumer and negative in winter. The months of sumer and winter are those that most influence the number of deaths in mainland Portugal.

Keywords: Climatic variability, mortality, air temperature, Portugal. 


\section{Introdução}

Há 4.600 anos na China o clima já era reconhecido como um dos factores naturais que mais condicionava a vida na Terra (Rortars, 1978). No mundo ocidental alguns dos efeitos que relacionam o clima e a saúde humana foram fundamentados na Grécia durante o século IV a.C. , por Hipócrates ${ }^{1}$. Em Portugal, somente na segunda metade do século XIX surgiram os primeiros estudos que relacionavam alguns efeitos do clima na saúde pública (Aтcorcrapo etal., 1999).

A influência do clima e das situações meteorológicas adversas no conforto e na saúde humana são áreas de estudo no domínio da Bioclimatologia Humana e da Biometeorologia. A fronteira entre estes dois domínios científicos não se encontra muito bem estabelecida e muitos autores e instituições não são consensuais na definição de Bioclimatologia Humana e Biometeorologia, utilizando as dois termos como sinónimos (ANRRAE, 2003) . O American Meteorological Society, no seu glossário digital, define Bioclimatologia e não Biameteorologia. Apluridiscipl inaridade que envolve estas duas ciências pode ser uma das causas para a inexistência de uma definição consensual.

O conhecimento científico dos efeitos do clima no conforto e na saúde humana não tem parado de aumentar: KaIKESIEIN (1991), KALKESIFIN et al. (1997), Benson et al. (2000), CGER (2001), Kourvas et al. (2004), Dessai (2004). Alguns dos efeitos directos nos seres humanos (vulnerabilidade) decorrentes do aumento da intensidade e da frequência de alguns fenómenos meteorológicos (perigosidade natural) são cientificamente reconhecidos: KALKESIEIN (1991), MaTZARAKIS et al. (1991), KAIKESIEIN et al. (1997), Bensan et al. (2000), Davis et al. (2002). As maiores incertezas estão mais relacionadas com os efeitos indirectos do clima na saúde: CGER (2001), Sanios et al. (2002), Dessai (2004), Kairras et al. (2004), TAaerius et al. (2007). Estudos recentes já mostraram que alguns tipos de doenças perante determinadas condições atmosféricas podem sofrer alterações no desenvolvimento ou na longevidade dos seus agentes patogénicos (Ganav et al., 2001, e Karrras et al., 2004). Estes cenários modificam muitas vezes a distribuição espacial de vectores de determinado tipo de dbenças e começam a emergir em diversos locais, doenças já irradicadas há décadas de certas partes do gldoo (Kairras et al., 2004) .

Actualmente, existe uma consciencial ização sobre as efeitos das alterações climáticas (IPCC, 2001;
CGER, 2001; SAnIos et al., 2002 e 2006; Błars et al., 2008), mas os desafios decorrentes dos cenários futuros que o clima pode provocar na saúde humana ainda não são claros. A variabilidade do clima conjugada com a vulnerabilidade humana perante algumas situações meteorrológicas adversas constitui o risco climático (Alcoforado, 2000). As preocupações envolventes a estas temáticas levam organizações e governos a implementar planos para melhorar a eficácia das políticas de prevenção, de controlo e redução de riscos para a saúde pública com origem em factores ambientais (PNAAS, 2008) .

\section{Metodologia}

A temperatura do ar é um dos elementos meteorológicas mais uti i izadbs para descrever o cl ina, sendo também um dos que mais influencia todos os processas biológicas e, consequentemente, todas as actividades humanas (SACARR̃̃o, 1981; PeixoIO, 1987).

Neste estudo analisa-se a mortalidade e a temperatura do ar (máxima, média e mínima) de Portugal continental (PC), como dojectivo de detectar relações significativas entre estas variáveis. Utilizamse as escalas temporais ano, estação do ano e mês. O período em estudo é de 1941 a 2005.

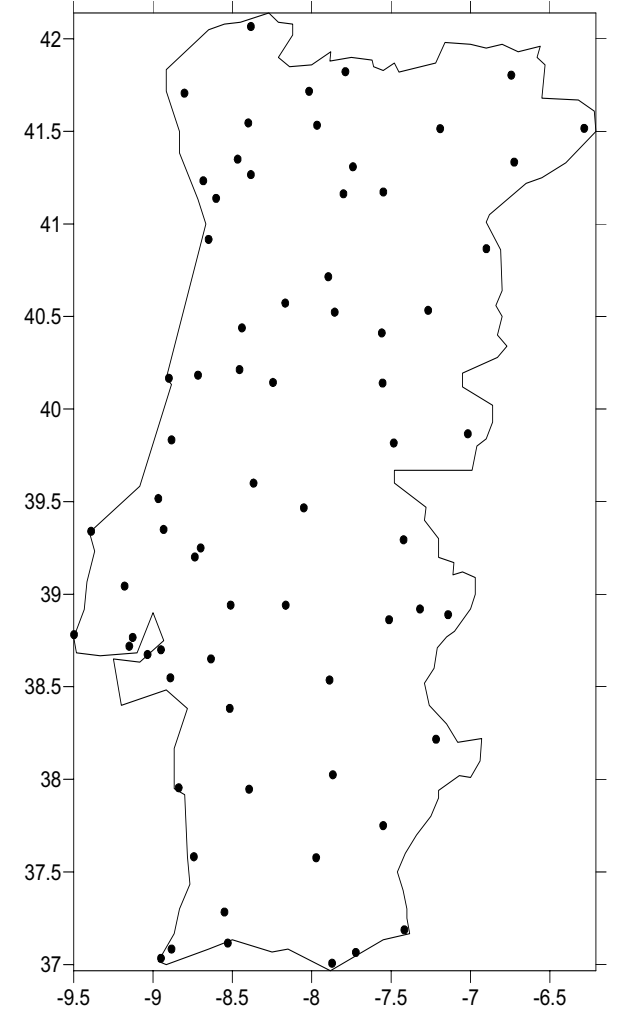

Fig. 1 - Representação das estaçães meteorológicas util izadas para calcular a temperatura média de Portugal continental.

No tratado "Das ares, águas e lugares", um das dbjectivos era precisamente incentivar os médicas viajantes que pretendiam arrar em terras estranhas a daservarem os ventos, as águas, o clima e os hábitos desses lugares. 
Apesar da sua pequena dimensão PC apresenta regiões clináticas distintas. A temperatura db ar neste território depende, essencialmente, do efeito de três factores físicos principais: a latitude, a proximidade ao oceano e a orografia (DAMEH, 1995; SAnOS et al., 2006) . Para determinar a temperatura média do ar de todb o território recorreu-se aos dadbs diários da temperatura máxima e mínima de várias estações meteorológicas (EM) do Instituto de Meteorologia, I.P. (IM, I.P.) . Adistribuição das EMutilizadas foi a mais homogénea possível, de forma a obter a melhor representatividade espacial da temperatura média do ar para o período em estudo atendendo aos factores referidos anteriormente (fig. 1). As análises são efectuadas com base nas anomalias (séries de média mula) da temperatura (máxima, média e mínima) de cada EM. São utilizadas as escalas temporais ano, estação do ano e mês. No caso das estações do ano utilizou-se a seguinte divisão: Primavera (Março, Abril e Mbio), Verão (Junho, Julho e Agosto), attano (Setembro, Outubro e Novembro) e Inverno (Dezembro, Janeiro e Fevereiro) . Na análise da variabilidade climática mensal retirou-se a variabilidade sazonal às séries. Este procedimento permite avaliar a tendência de longo prazo nas anomalias das séries mensais; é efectuado retirando a cada mês de cada ano a média de todos as anos, ou seja, ao Janeiro de 1941 retirase a média dos Janeiros de 1941/2005, ao Fevereiro de 1941 retira-se a média dos Fevereiros de 1941/2005, etc.

Os dados utilizados na análise da mortalidade para PC são mensais e provenientes da base de dados do InstitutoNacional de Estatística (biblicteca digital - $\mathbb{I N E})^{2}$ e referem-se a todas as causas de óbito. 0 acesso a estes dados através deste procedimento não é prático e, além disso, não estão disponíveis os dadas da mortalidade de PC para escalas temporais mais curtas, por exemplo, diários. A utilização de dados da mortalidade mensal é um factor condicionante para as metas que se pretendiam alcançar neste estudb, considerandb-se que a escala diária valorizaria a determinação de relações desfasadas com várias variáveis meteorológicas distintas, passíveis de previsão (Młpres, 2007) . As estatísticas referentes à mortalidade do banco de dados do INE apresenta como conceito para óbito a "Cessação irreversível das funções do tronco cerebral" ${ }^{3}$. Para a análise da variabilidade da mortalidade foram efectuados os mesmos procedimentos estatísticos aplicados à análise da variabilidade da temperatura do ar.

É efectuada uma análise de correlações entre as anomalias das séries da mortalidade e da temperatura. São determinadas as correlações das variáveis para desfasamentos nulos, au seja, para o mesmo instante. A significância das correlaçães determinadas é testada para o nível de significância de 0.05 (intervalo de confiança de 95\%) .

A tendência linear, apesar de se poder efectuar, nem sempre é a que melhor se ajusta à variabilidade das séries. Neste estudb, e sendb este o caso, utilizarse para estimar as tendências das séries da mortalidade e da temperatura uma técnica recente e poderosa para análise de séries temporais incorporando os elementos clássicos da análise espectral e atras características de processamento de sinais que permitem prescrever às séries comportamentos sinusoidais que não se restrinjam apenas à aplicação de senos e cosenos. O método de Análise Espectral Singular (SSA) (Vhrnad et al., 1992) é baseado na construção de filtros denominados data-adaptive, ou seja, em que a forma dos fil tros se adapta à própria evolução da série. Esta técnica de análise permite decompor uma série temporal em várias componentes (também séries temporais) com características de periodicidade mais simples e com óbvias vantagens na eliminação do nuído da série original. A SSA permite também extrair da série, caso existam, componentes de tendência não lineares, mais realistas do que as usuais tendências lineares, por possibilititarem a existência de vários períodos em fase positiva e negativa. O método, revelandb componentes significativas por aplicação de testes de significância, pode também ser usadb na previsão da própria série (Anures et al., 2001) . A implementação da SSA parte da construção da chamada matriz trajectória de uma série temporal de comprimento $N$, formada a partir de uma janela de tamanho $M$, nunca superior a 1/3 dos dados de cada série de entrada (Barr et al., 1994).

\section{Variabilidade da temperatura do ar em Portugal Continental (1941 a 2005)}

O clima da Terra está em constante mudança. O conhecimento paleoclimático destas mudanças (alterações cceanográficas e climáticas) no planeta pode ser fundamentado pelo estudo das foraminíferos fósseis ${ }^{\sharp}$. É passivel a partir das dados de isótopos de

\footnotetext{
www.ine.pt

Enbora a determinação da morte por paragem cardio-respiratória não suscite normalmente qualquer dúvida ao médico e conduza à assinatura do cert ificicado de óbito, o desenvolvimento dos auidados de saúde tomou a determinação da morte mais difícil, deixandb de ser a paragem cardio-respiratória o único factor determinante para a morte do indivíduo (Lei n. ${ }^{\circ}$ 12/93, de 22 de Abril)

Os foraminíferos são microorganismos unicelulares predominantemente marinhos. Após a morte as suas carapaças calcárias depositam-se nos fundos oceânicos; estes sedimentos contêm a informação da temperatura e da salinidade das águas dos mares na época em que viveram.
} 
oxigénio e carbono contido nos foraminíferos fósseis reconstruir as alterações climáticas ao longo da história da Terra. Estas alteraçães climáticas estão mais ou menos bem identificadas e estão associadas a causas naturais (Pexuro e Orri, 1992) .

No início do século XX intensificou-se a observação instrumental de diversas variáveis meteorológicas. Nas últimas décadas deste século verificou-se uma tendência no aquecimento global, devido ao aumento da temperatura do ar à superfície (IPCC, 2001). Nas análises efectuadas pelo PROJECTO SIAM, ao clima de Portugal dos séculos XX e XXI, mostra-se que a variação da temperatura média de Portugal é semelhante à tendência do aquecimento global (Sanos et al, 2002 e 2006) .

No presente estudo sobre a análise da variabilidade das temperaturas médias do ar de PC
(1941/2005) é também identificada uma tendência de aumento. As tendências lineares associadas a cada série da temperatura do ar máxima, média e mínima, são respectivamente $0.74,0.72$ e $0.69^{\circ} \mathrm{C}$, ou seja, $0.0114,0.011$ e $0.0106^{\circ} \mathrm{C} / \mathrm{ano}$, respectivamente. A média anual das mesmas temperaturas do ar para este períodb e para toob espaço territorial é 20.3, 15.1 e $9.9^{\circ} \mathrm{C}$. No entanto, a simples doservação das séries de anomalias anuais das temperaturas do ar em PC mostra que a tendência linear não será a mais adequada para avaliar a sua variabilidade neste período (figs. 2, 3 e 4) . A aplicação do método SSA permite extrair destas séries da temperatura média anual uma tendência não linear, mais ajustada à sua variabilidade, e identificar períodos distintos ou ascilaçães na sua evolução.

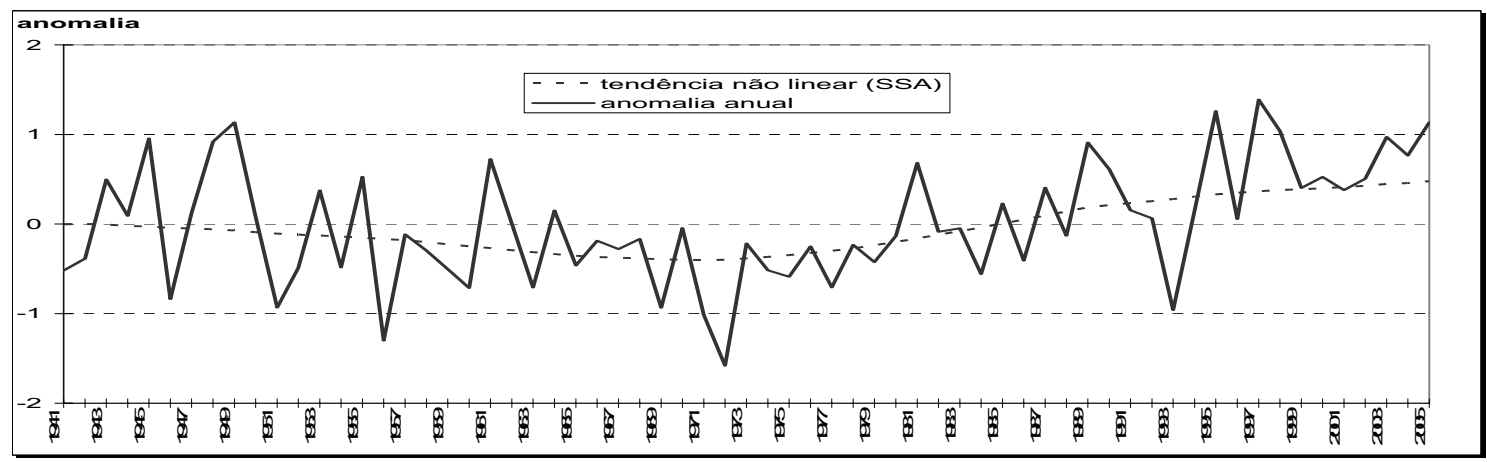

Fig. 2 - Variabilidade anual da temperatura máxima em Portugal continental e tendência não linear.

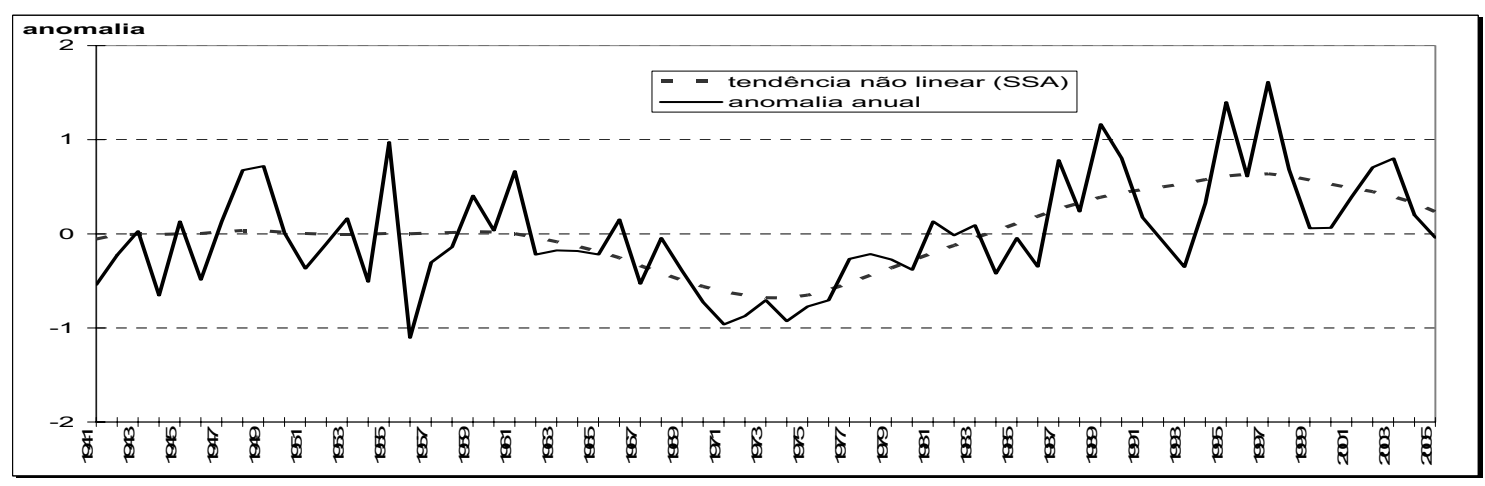

Fig. 3 - Variabilidade amual da temperatura média em Portugal continental e tendência não linear.

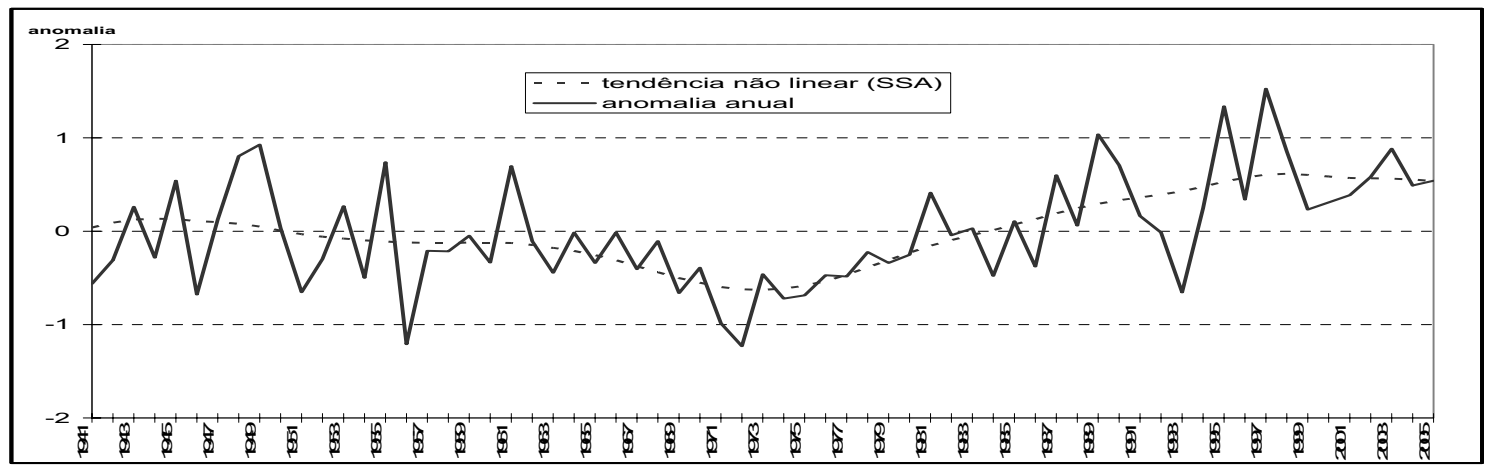

Fig. 4 - Variabilidade anual da temperatura mínima em Portugal Continental e tendência não linear. 
Verifica-se um comportamento semelhante na evolução das tendências das temperaturas médias anuais de Portugal continental: as tendências estiveram abaixo da média desde 1941 até 1983/ 1985 (temperaturas médias e mínimas/temperaturas máximas, respectivamente) e acima das médias desde estas datas até 2005. Apesar das tendências da temperatura mínima serem superiores à média desde 1983 até ao fim do períoob, verifica-se uma tendância de decréscimo a partir de 1997; neste mesmo período a temperatura máxima continua a aumentar. A inversão das tendências das temperaturas médias, máximas e mínimas, ocorreu entre 1972 e 1974.
A análise das tendências das séries mensais da temperatura média (máxima, média e múnima) de PC, efectuada pelo mesmo método, revela tendências similares às anuis (figs. 5, 6e 7) .

Nesta análise mensal é passível verificar que a ocorrência de anomal ias superiores a 3.0 e inferiores a -3.0 surgem com alguma regularidade ao longo das séries (máxima e mínima). No entanto, anomalias mensais inferiores a -3.0 , para o caso da temperatura máxima, não ocorrem desde 1994.

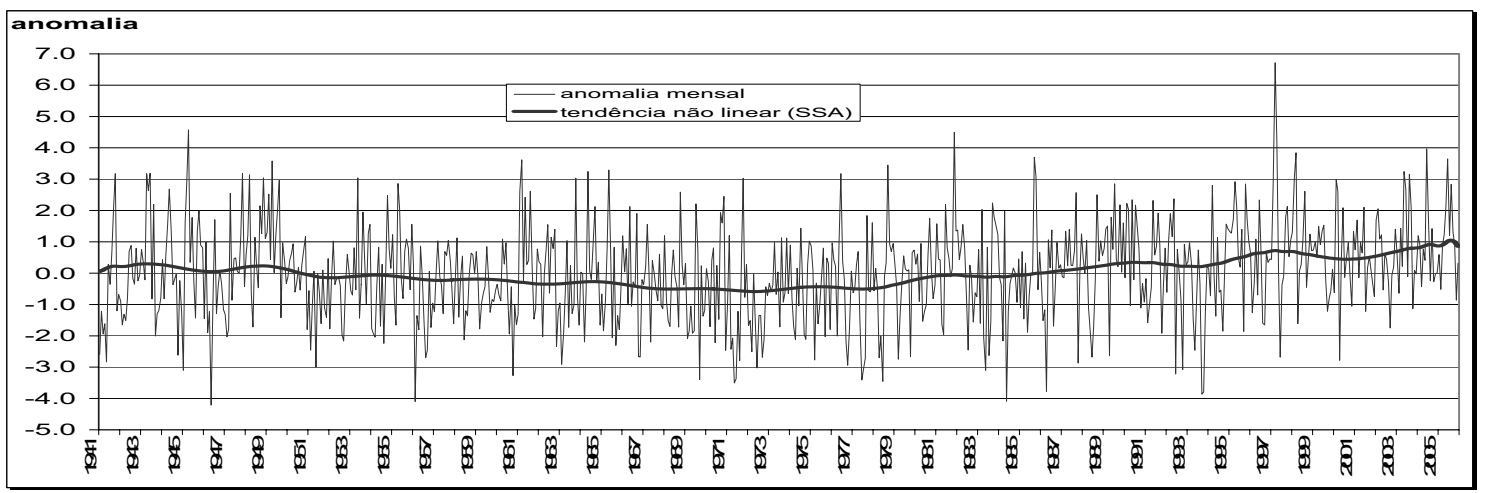

Fig. 5 - Variabilidade mensal da temperatura máxima em Portugal continental e tendência não linear.

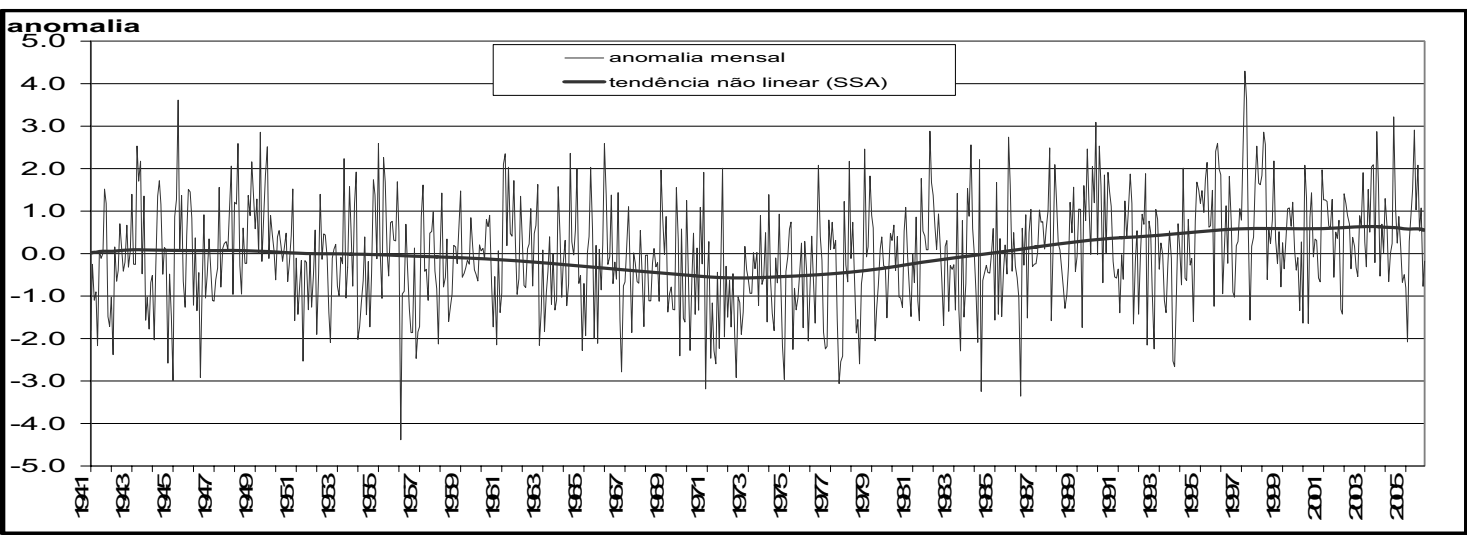

Fig. 6 - Variabilidade mensal da temperatura média em Portugal continental e tendência não linear.

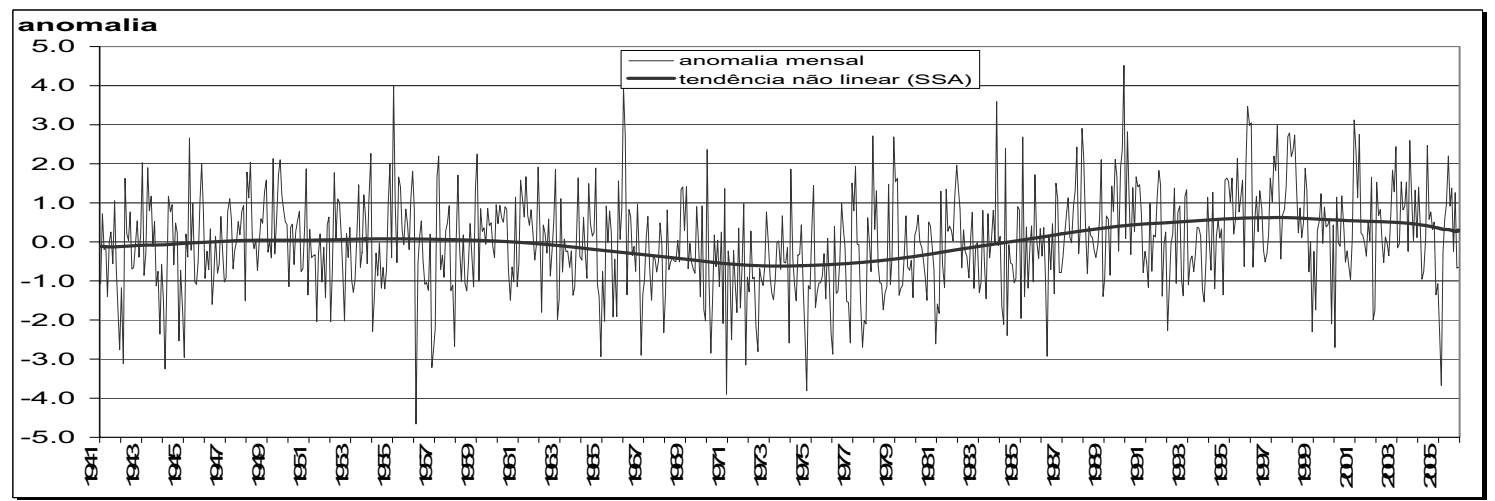

Fig. 7 - Variabilidade mensal da temperatura múnima em Portugal Continental e tendência não linear. 


\section{Variabilidade da mortalidade em Portugal Continental (1941 a 2005)}

Segundo dados do INE (2007) as taxas da mortalidade anual em Portugal, desde o início do século XX, apresentam um declínio considerável ${ }^{5}$. A contribuição de diversos factores, alguns de ordem sócio-económica, foram fundamentais para a diminuição da mortalidade geral em Portugal. Entre eles salientam-se as melhorias das condições de vida da população, aumento e melhores acessos aos cuidados de saúde pública, a diminuição da mortalidade infantil e o consequente aumento da esperança média de vida dos portugueses. anual ocorre durante os meses mais frios do ano e o mínimo durante a época estival. No entanto, durante o Verão é possível identificar frequentemente um pequeno acréscimo na mortalidade mas de muito menor expressão que a mortalidade dos meses mais frios (fig. 8).

Para analisar de forma mais detalhada a mortalidade mensal do período em estudo (1941/ 2005) fez-se corresponder cada total mensal a unidades de tempo iguais de 30 dias. Assim, ao número de óbitos mensal referente aos meses com 31 dias foi aplicado um factor de 0.96, aos meses com 29 dias o factor de 1.03 e aos meses com 28 dias o factor de 1.07. Finalmente, foi calculada a

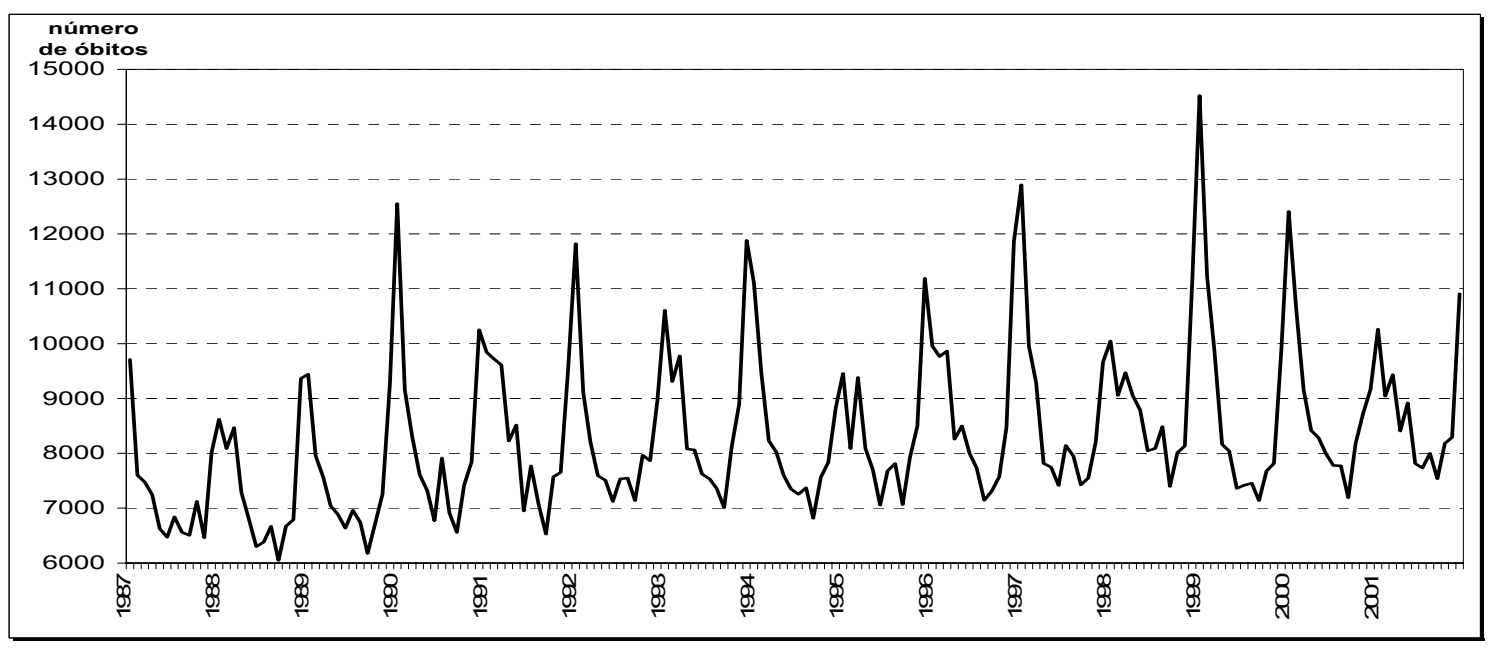

Fig. 8 - Evolução da mortalidade mensal em Portugal Continental. Fonte: MARQUES, 2007

A evolução da mortalidade em Portugal tem sido acompanhada através de diversos estudos, como, por exemplo, o "Risco de Morrer em Portugal" editado pela Direcção Geral de Saúde (CAIARTNo, 2000, 2001 e 2002) . Nas últimas décadas os acessos à saúde pública aumentaram e a implementação de unidades de saúde variou de forma directa com a unbanização/ litoralização (SANIANA et al., 2004) mas esta assimetria não revela discrepância para a mortalidade geral entre as diferentes regiões em PC (Nocteira et al. , 2007).

A mortalidade em Portugal mostra uma variação sazonal, identificada por diversos autores e entidades públicas (PINHIRO, 1990; FÃC̃̃o et al. , 2004; INE, 2007) e que se mostra na figura 8 (Mkpows, 2007) .

A variação mensal da mortalidade em PC é muito idêntica à dos países das latitudes médias e altas do hemisfério norte (Мқakenach et al. , 1992; MaKFE et al., 1998; AIBHRDI et al., 1998; G GMEL et al., 2002; CtrrItro et al., 2002; DanaIDsan, 2002; Winkinsan et al., 2004). Mostra-se que o máximo mortalidade média para cada mês, o que se apresenta na figura 9.

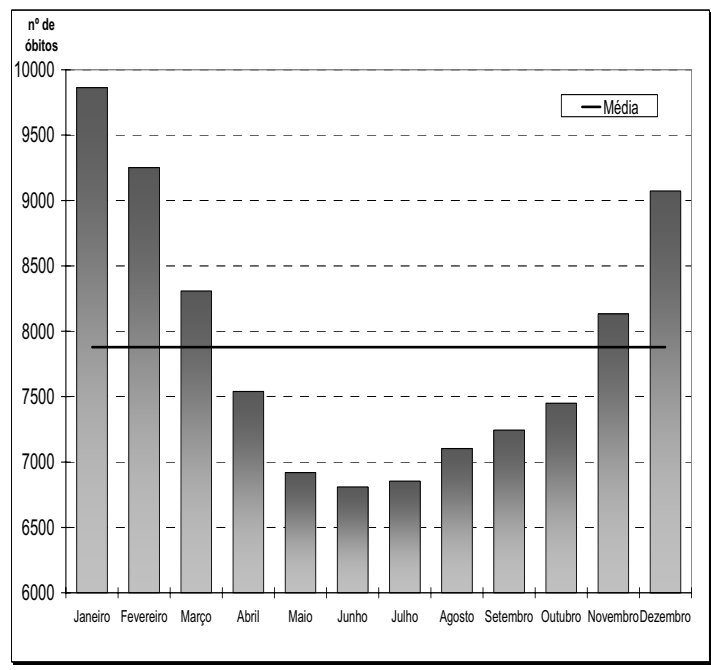

Fig. 9 - Variação média mensal da mortalidade em Portugal Continental (1941-2005) . 
É evidente o forte contraste da média mensal da mortalidade entre os meses mais quentes e os mais frios do ano. A variação mostra os meses de Novembro a Março com valores acima da média, com o pico da mortalidade anual a ocorrer em Janeiro. Nos restantes meses o número médio de óbitos está abaixo da média e os valores mensais mais baixos da mortalidade anual ocorrem em média no mês de Junho. Pode concluir-se, assim, que a mortalidade em PC, no período analisado, foi superior durante os meses mais frios do ano (Novembro, Dezembro, Janeiro, Fevereiro e Março).

A anál ise da variabilidade da mortal idade anual em PC, para o período em estudo, revela a anomalia mais elevada em 1941 (fig. 10), assim como a dos vários anos seguintes a este. participou nesta guerra, mas a mortalidade elevada drante estes anos poderá reflectir alguns dbs saus efeitos indirectos, verificandb-se que as anomalias anvais da mortalidade são positivas ao longo de toda a década de 40. A aplicação do métoob SSA permite identificar que depois de 1952 a tendência da mortalidade em PC passa a ser negativa. A partir de 1992 até ao final do período (2005) a tendência passa a ser positiva, mas foi a partir de 1984 que se deu a inversão da tendência passando, desde então, a aumentar.

A análise das anomalias mensais da mortalidade para $\mathrm{PC}$, depois de retirada a variabilidade sazonal, revela uma evolução idêntica à anul (fig. 11) . Mbstrase, apesar disso, que algumas das anomalias mais elevadas, além das registadas nas primeiras décadas (anomalias superiores a 3000 mortes no mês) ${ }^{6}$, já

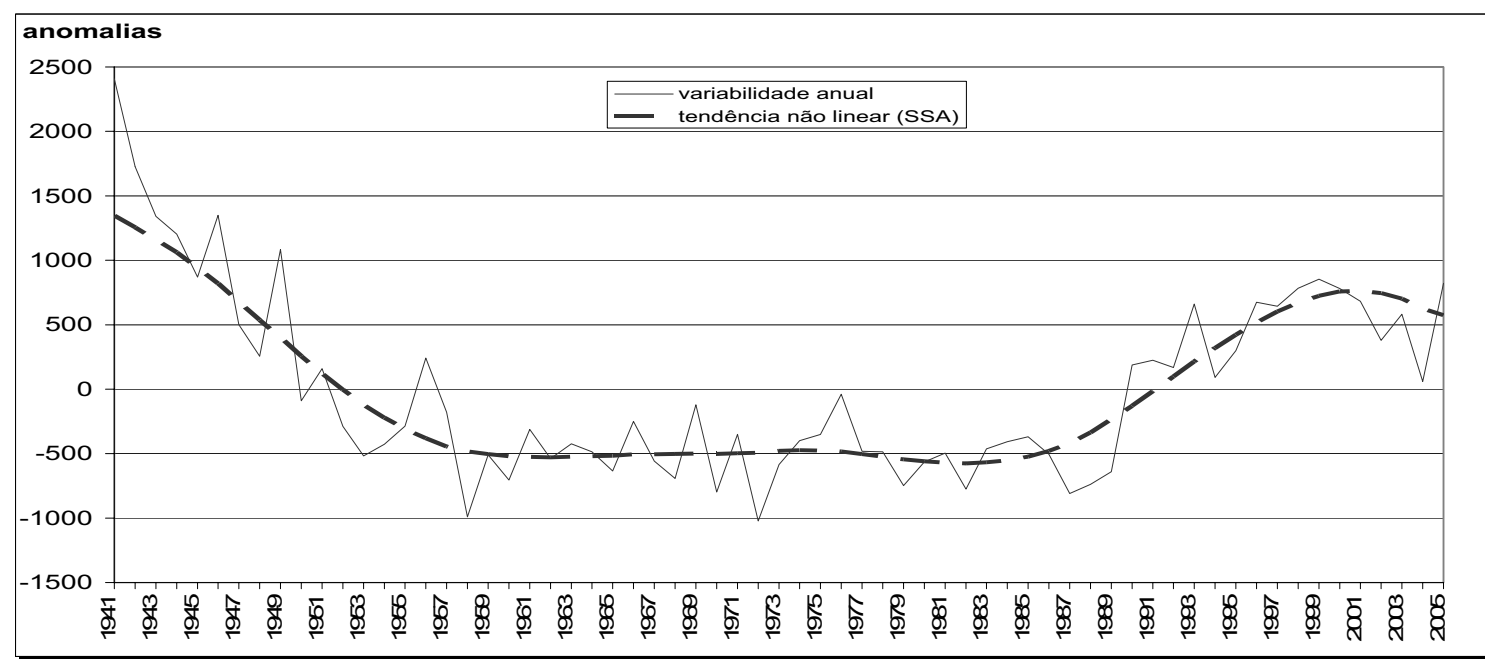

Fig. 10 - Variabilidade da mortalidade anual em Portugal Continental e tendência não linear.

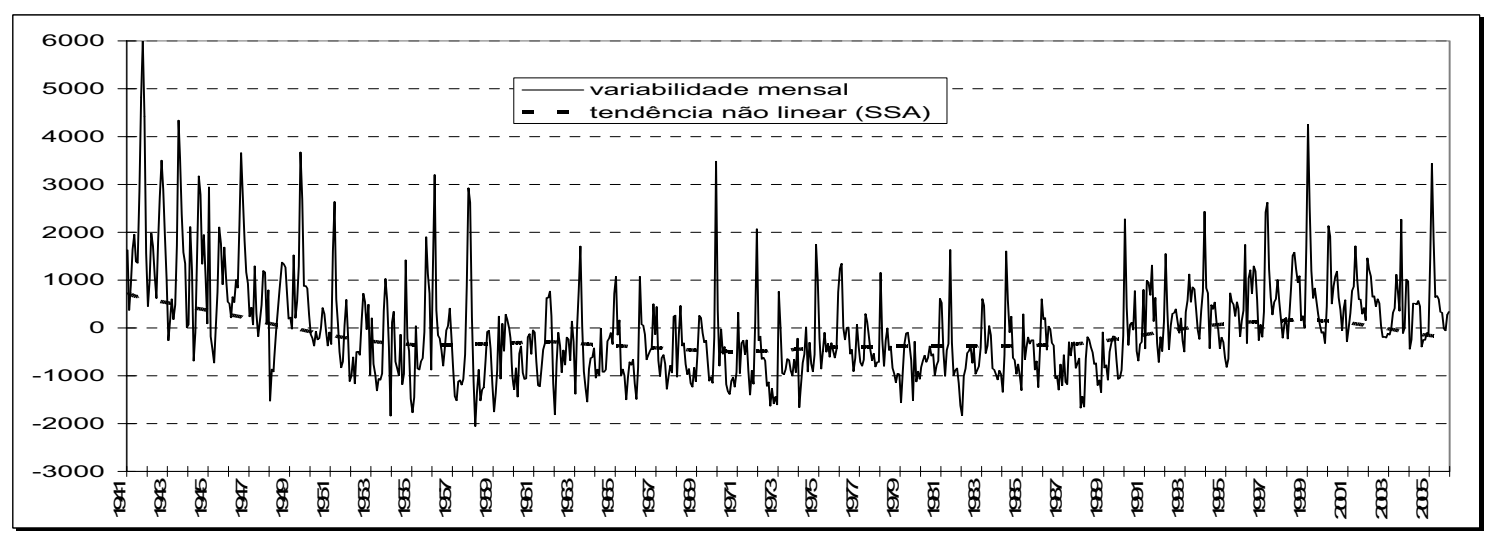

Fig. 11 - Variabilidade da mortalidade mensal em Portugal continental e tendência não linear.

No primeiro quinquénio desta década vivia-se, em quase toda a Europa, os efeitos da Segunda Guerra Mundial (1939-45) mesmo para os países não envolvidas directamente no conflito. Portugal não ocorreram nos últimos anos (Janeiro de 1999 e Fevereiro de 2005) .

No Quadro I apresentam-se as anomalias mensais da mortalidade a partir de um certo limiar (superior a

\footnotetext{
O valor corresponde a cerca de três desvios padrão para o mês (um desvio padrão = 1046 ábitos)
} 
3000 abitos) . Esta anál ise permite concluir que estes valores extremos ocorreram no autono (31\%), Verão (38\%) e Inverno (31\%). A análise temporal mostra que nos primeiros anos estes valores extremos ocorreram no outono, nos anos seguintes nos meses de Verão e mais recentemente nos meses de Inverno. Nos meses de Março, Abril e Maio (Primavera) não existem anomalias superiores a 3000 óbitos/mês.

Entre os meses do período 1941/2005 estas anomalias mais elevadas ocorreram inicialmente durante os meses de Outono (31\%), passando para as meses de Verão (38\%) e pasteriormente durante as meses de Inverno (31\%). Nos meses de Março, Abril e Maio (Primavera) não existem ananalias superiores a 3000 óbitas/mês.

QuADRo I - Casos de mortalidade mensal elevada em Portugal Continental.

\begin{tabular}{|c|c|c|c|}
\hline ANO & MÉS & Óbitos & ANOMALIA \\
\hline 1941 & Setembro & 12064 & 4820 \\
\hline 1941 & Outubro & 13758 & 5998 \\
\hline 1941 & Novembro & 12557 & 4423 \\
\hline 1942 & Setembro & 10748 & 3504 \\
\hline 1943 & Julho & 11478 & 4340 \\
\hline 1943 & Agosto & 10953 & 3553 \\
\hline 1944 & Julho & 10315 & 3177 \\
\hline 1946 & Agosto & 11059 & 3659 \\
\hline 1949 & Julho & 10814 & 3676 \\
\hline 1956 & Fevereiro & 11932 & 3203 \\
\hline 1969 & Dezembro & 12933 & 3483 \\
\hline 1999 & Janeiro & 14524 & 4251 \\
\hline 2005 & Fevereiro & 12164 & 3435 \\
\hline
\end{tabular}

Relações entre temperatura e mortalidade em Portugal Continental.

Sabe-se que as seres vivos possuem determinados limites de tolerância à temperatura (por ex. , Słcatrão, 1981; ANDRADE, 2003). mínima (fig. 12). Verifica-se que os máximos da mortalidade ocorrem para as temperaturas do ar mais baixas. O $2^{\circ}$ pico de mortalidade ocorre para as temperaturas mais elevadas. A mesma análise permite identificar um patamar em que o número de óbitos é muito baixo (óptimos térmicos). Esse patamar é diferentepara:

- As temperaturas máximas $\left(18-29^{\circ} \mathrm{C}\right)$, com o extremo térmico $23^{\circ} \mathrm{C}$,

- As temperaturas médias $\left(15-23^{\circ} \mathrm{C}\right)$, com o extremo térmico $19^{\circ} \mathrm{C}$,

- As temperaturas mínimas $\left(10-16^{\circ} \mathrm{C}\right)$, com o extremo térmico $13^{\circ} \mathrm{C}$.

Salienta-se o facto da amplitude, nestes intervalos térmicos, ser maior na variação da temperatura máxima que nas temperaturas mínima e média. Este facto pode evidenciar uma melhor adaptação da população à variação da temperatura máxima do que à variação das restantes temperaturas. SAcARR̃̃o (1981) mostra que, em geral, os óptimos térmicos? dos seres vivos estão frequentemente mais próximas das temperaturas máximas do que das mínimas. Para além de limiares térmicos de temperatura de ar definidos, a mortalidade aumenta consideravelmente, mas os declives das variações mostram que o incremento do número de óbitos é superior com a subida de temperatura (FALC̃̃o, 1988; GARCIA, 1999; DESSAI, 2003; DIAZ, 2006).

A $2^{a}$ análise efectuada neste estudo resulta da aplicação do métoob SSA para identificar tendências não lineares na variabilidade da temperatura e da

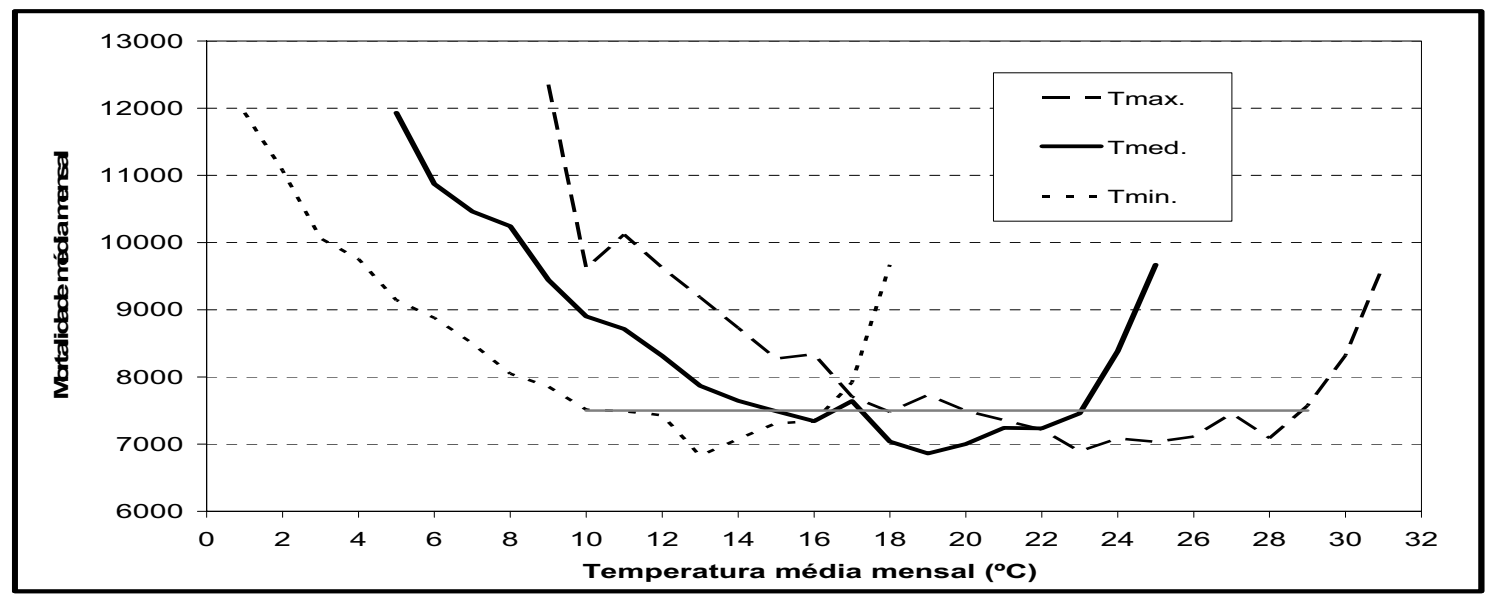

Fig. 12 - Variação média mensal da mortalidade com a temperatura do ar em Portugal Continental (1941-2005) .

Numa primeira análise pretendem identificar-se patamares e extremos da temperatura susceptíveis de influenciar a mortalidade. A distribuição da mortalidade, analisada no período 1941/2005, é semelhante para as temperaturas máxima, média e mortalidade no período 1941/2005. A análise revela um comportamento semelhante de diminuição tanto da mortalidade como da temperatura do ar até ao início da década de 60 (fig. 13). Apartir daí, e atéao início da década de 80, onúmero de dbitos estabi i izau,

Temperaturas às quais as espécies vivas mostrammais valências. 


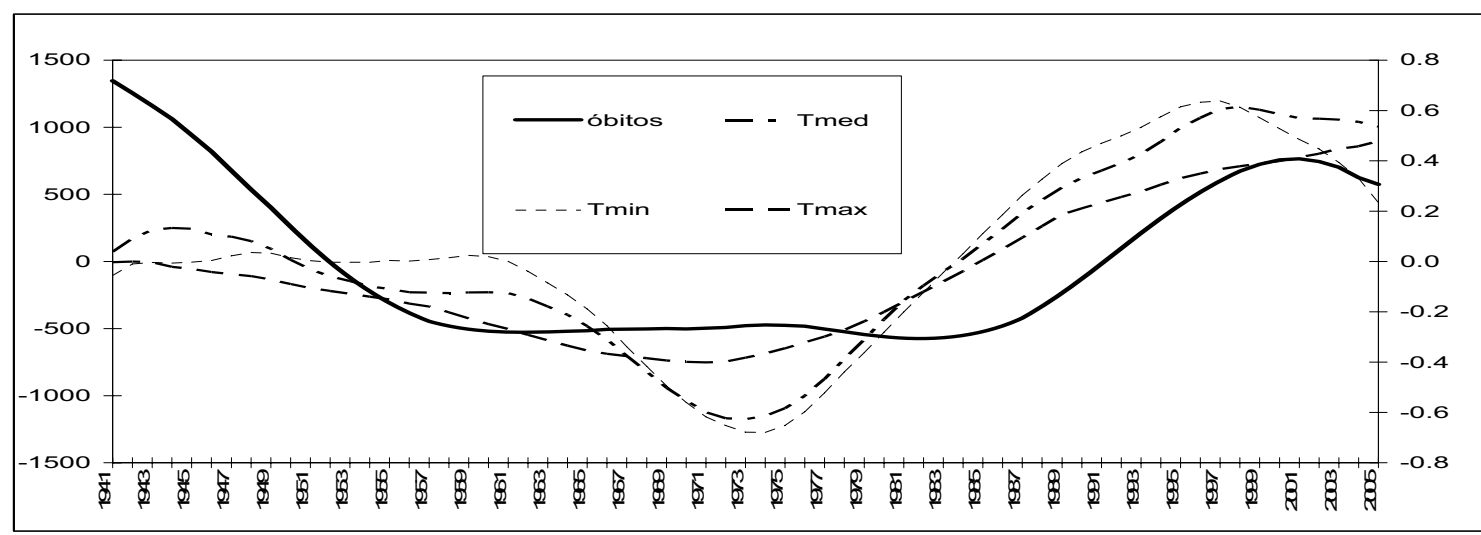

Fig. 13 - Tendências não lineares anuais da mortalidade e da temperatura do ar em Portugal continental.

enquanto a temperatura continuou a diminuir até ao princípio da década de 70. A partir destas décadas, respectivamente, ambas as tendências são de aumento. Enquanto a temperatura máxima mantém a tendência de aumento, as tendências da temperatura média e mínima e da mortalidade diminuem durante o segundo quinquénio da década de 90.

No QHrro II apresentam-se as correlações entre a mortalidade e a temperatura do ar (méxima, média e mínima) para o ano, estação do ano e mês. São estatisticanente significativas as conrelaçuess superiores a 0.25 considerando-se, para este número de dadbs, intervalos de confiança de $95 \%$ (apresentam-se a negrito as comrelaçães significativas). Verifica-seque as correlações anuais entre a mortalidade e a temperatura são fracas, o que mostra que a escala temporal amual não é provavelmente a melhor para identificar relações entre temperatura emortalidade. A única relação significativa, mas relativamente fraca, ocorre entre a temperatura máxima e a mortalidade; esta correlaçãoé positiva, au seja, temperatura máxima anual acima da média tende a ocorrer com mortalidade também acima da média e vice-versa.

A análise das correlações a escalas temporais mais artas, sazonais, revela que:

- A mortalidade de Verão está associada às temperaturas mínima, máxima e média de modo directo, significando que a ocorrência destas temperaturas acima da média tende a originar mortalidade acima da média e vice-versa (temperaturas abaixo da média tendem a originar mortalidade abaixo da média;

- A mortalidade de Inverno está associada de modo inverso com a temperatura mínima na

QuArRo II - Correlação da mortalidade com a temperatura do ar (1941 - 2005) .

\begin{tabular}{|c|c|c|c|c|}
\hline \multirow{2}{*}{\multicolumn{2}{|c|}{ Escala temporal }} & \multicolumn{3}{|c|}{ Temperatura } \\
\hline & & Mínima & Média & Máxima \\
\hline \multicolumn{2}{|c|}{ Ano } & 0.15 & 0.23 & 0.28 \\
\hline \multirow{4}{*}{ Estação do ano } & Inverno & -0.33 & -0.24 & -0.02 \\
\hline & Primavera & 0.16 & 0.07 & 0.01 \\
\hline & Verão & 0.43 & 0.49 & 0.49 \\
\hline & Outono & -0.11 & -0.03 & 0.05 \\
\hline \multirow{12}{*}{ Meses } & Janeiro & -0.45 & -0.43 & -0.25 \\
\hline & Fevereiro & -0.49 & -0.38 & -0.16 \\
\hline & Março & -0.08 & -0.08 & -0.06 \\
\hline & Abril & 0.13 & 0.04 & -0.02 \\
\hline & Maio & 0.01 & -0.05 & -0.09 \\
\hline & Junho & 0.47 & 0.52 & 0.51 \\
\hline & Julho & 0.26 & 0.30 & 0.30 \\
\hline & Agosto & 0.33 & 0.36 & 0.35 \\
\hline & Setembro & 0.07 & 0.06 & 0.06 \\
\hline & Outubro & -0.12 & 0.00 & 0.09 \\
\hline & Novembro & -0.28 & 0.01 & -0.23 \\
\hline & Dezembro & -0.30 & -0.28 & -0.20 \\
\hline
\end{tabular}


mesma estação do ano, significando que temperatura mínima abaixo da média tende a ocorrer com mortalidade acima da média e viceversa (temperatura mínima acima da média tende a ocorrer com mortalidade abaixo da média.

Fm módulo as correlaçães entre a mortalidade e a temperatura são superiores no Verão. Pode também concluir-se desta análi ise que nesta estação do ano a mortalidade é influenciada tanto pela temperatura diurna como nocturna. Nas estações intermédias (Primavera e Outono) não se detectam correlações significativas entre temperatura e número de doitos.

A análise mensal mostra dois grupos correlacionados significativamente: o primeiro associadb ao períodb mais quente do ano (Junho, Jilho e Agosto) e o segundo aos meses mais frios (Novenbro, Dezentoro, Janeiro e Fevereiro). Nos meses intermédios (Narç̧o, Abril, Maio e Setembro, autubro) não se detectam relações estatisticamente significativas entre a mortalidade e a temperatura do ar.

As correlações da mortalidade durante os três meses de Verão (Junho, Julho e Agosto) são significativas com todas as temperaturas do ar. A temperatura média é a que mais se correlaciona com a número de mortes, mas muito próxima da temperatura máxima e seguida da temperatura mínima. Esta relação mostra a importância da temperatura do ar ao longo de todo o dia durante estes meses (períodos diurnos e nocturnos), destacando-se entre eles o mês de Junho camo o que mais influencia o número de doitas.

Durante os meses de Novembro, Dezembro, Janeiro e Fevereiro as correlaçães significativas da mortalidade com a temperatura são negativas. A temperatura mínima do ar nestes meses é a que apresenta correlações superiores, emmóoullo, coma mortalidade. O mês de Janeiro é o mais relevante, apresentando correlações significativas da mortalidade com todas as temperaturas do ar (máxima, média e múnima) . É, portanto, este o mês em que a variação da temperatura ao longo do dia assume maior importância na mortalidade.

Emmódulo as correlaçães são mais fortes durante o mês de Junho do que durante o mês de Janeiro. Verifica-se assim, que a variabi 7 idade da temperatura do ar durrante o mês de Junho explica mais variância da mortalidade que a do mês de Janeiro, apesar do número de óbitos durante o mês de Junho ser muito mais baixo que durante o mês de Janeiro.

Analisam-se em seguida, períodos com duração mensal em que ocorreu mortalidade excessiva (anomalias >3000 mortes, cerca de 3 desvios padrão) e as respectivas anomalias da temperatura do ar (méxima, média e mínima) no mesmo período (Quarpo III) .
QIARRO III - Casos de mortalidade mensal elevada e respectivos desvios da temperatura (1941-2005) .

\begin{tabular}{|c|c|c|c|c|c|}
\hline \multirow{2}{*}{ Ano } & \multirow{2}{*}{ Mês } & \multicolumn{4}{|c|}{ Desvios } \\
\cline { 3 - 6 } & & Anomalia & Tmax & tmed & tmin \\
\hline 1941 & Set & 4820 & 2.1 & 1.5 & 1.1 \\
\hline 1941 & Out & 5998 & 3.2 & 1.2 & -0.7 \\
\hline 1941 & Nov & 4423 & -1.2 & -1.5 & -1.7 \\
\hline 1942 & Set & 3504 & -0.4 & -0.2 & 0.0 \\
\hline 1943 & Jul & 4340 & -0.8 & -0.5 & -0.1 \\
\hline 1943 & Ago & 3553 & 2.2 & 1.4 & 0.5 \\
\hline 1944 & Jul & 3177 & -0.4 & -0.5 & -0.6 \\
\hline 1946 & Ago & 3659 & -1.3 & -1.0 & -0.8 \\
\hline 1949 & Jul & 3676 & 2.0 & 1.9 & 1.7 \\
\hline 1956 & Fev & 3203 & -4.1 & -4.4 & -4.6 \\
\hline 1969 & Dez & 3483 & -1.2 & -1.6 & -2.0 \\
\hline 1999 & Jan & 4251 & 0.7 & 0.3 & -0.2 \\
\hline 2005 & Fev & 3435 & -0.5 & -2.1 & -3.7 \\
\hline
\end{tabular}

Verifica-se que a frequência das ocorrências de valores extremos da mortalidade nos meses da década de 40 émuito superior à frequência de valores extremos nos anos subsequentes, confirmando a mortalidade elevada nesta década, já verificada a nível anul. Neste período os meses que mais contribuíram para a mortalidade foram os de Jilho, Agosto e Setembro. Apás esta década os maiores desvios da mortalidade emrelação à média verificaram-se emmeses de Invemo. Para o caso mais recente de mortalidade elevada (Fevereiro de 2005) contriburiram tanto as temperaturas máximas como as mínimas (e consequentemente as médias) abaixo da média; entre estas verifica-se que foi a temperatura mínima que mais contribuiu para a mortalidade deste caso extremo.

\section{Canclusões}

Neste estudo foi analisada a variação da mortalidade com a temperatura do ar (méxima, média emínima) , para toobo tenritório de Portugal continental no período de 1941 a 2005. Mastrou-se que o número de óbitos é mais elevado comas temperaturas extremas, coma mortalidade a atingir valores mais el evados para as temperaturas muito baixas. O número de doitos é particularmente baixo quandb as temperaturas mensais variam entre 10 a $16{ }^{\circ} \mathrm{C}$ na múnima, 15 a $23{ }^{\circ} \mathrm{C}$ na média e 18 a $29^{\circ}$ Cna méxima. Considera-se, assim, que estes são os intervalos que identificammaior tolerância à temperatura doservada em Portugal. Para além destes patamares a mortalidade aumenta consideravelmente, identificandb-se uma taxa de aumento superior com a subida da temperatura do ar.

Verificou-se que a aplicação de ummétoob linear para avaliar as tendências das variáveis em estudo (mortalidade e temperatura do ar) não seria o mais indicado. A utilização do método SSA, não linear, permitiu identificar as datas de inversão associadas a cada uma das tendências. Entre 1985 e 1997 as tendências de todas as variáveis (mortalidade e temperatura do ar, máxima, média e mínima) são de aumento, sendo este o período mais longo em que se 
verifica um comportamento tendencial semelhante entre toolas as séries.

A análise de correlações entre a temperatura do ar e a mortalidade em Portugal continental permite concluirque:

l A temperatura máxima do ar é a que mais influencia a mortalidade do ano. A relação varia no mesmo sentido, ou seja, temperatura máxima anual acima da média tende a ocorrer com mortalidade também acima da média e vice-versa.

l É no Verão que se verificam as correlaçães mais elevadas entre a temperatura e a mortalidade. Estas correlações são positivas e verificam-se para a temperatura máxima, mínima e média, revelando que a mortalidade nesta época do ano é influenciada tanto pelas temperaturas diumas como nocturnas. A análise mensal mostra o mesmo tipo de relações em todos os meses da estação do ano (Junho, Jilho e Agosto) , e que é o mês de Junho o que apresenta as correlações mais significativas com a ocorrência de mortalidade.

l No Inverno a mortalidade só revela relações significativas coma temperatura mínima. Esta relação énegativa, au seja, temperatura mínima abaixo da média tende a ocorrer com mortalidade acima da média e vice-versa. A análise mensal revela que, para além dos meses de Invemo (Dezenbro, Janeiro e Fevereiro) , em Novembro também se verifica o mesmo tipo de relação. Em Janeiro detectam-se também correlações significativas, negativas, coma temperatura máxima e média, mostrando que a mortalidade neste mês é influenciada tanto pelas temperaturas diumas como noctumas.

Tendb-se estabelecido relações importantes entre a variabilidade da temperatura do ar e da mortalidade a nível anual, sazonal e mensal, considera-se importante determinar a influência da temperatura na mortalidade em Portugal a escalas temporais mais curtas, nomeadamente a diária. Este será objecto de um estudo futuro e terá em conta resultados dbtidos anteriormente que relacionam as condições climáticas de Inverno e a mortalidade diária para o distrito de Lisboa (Mkpoes, 2007). A possibilidade de se desenvolver um modelo de previsão diária da mortalidade através de correlações desfasadas numa fase futura é o principal dojectivo destes estudos que, posteriormente, poderá ser desenvolvido espacialmente para várias regiões de Portugal Cantinental.
Tendo em conta que a influência da atmosfera sobre os seres humanos se exerce de forma combinada, será também importante detectar relaçães da mortalidade com outras variáveis meteorológicas (e.g. pressão atmosférica, humidade, vento, etc.) e mesmo com diferentes tipos de estado do tempo. Neste aspecto, a uti l ização de índices, que além de integrarem variáveis meteorológicas integram também a termofisiologia humana (por ex. , o vestuário e as componentes do balanço energético do corpo humano), poderão traduzir-se num aumento das correlações com a mortalidade e melhorar a capacidade de previsão de um modelo.

\section{Referências bibliográficas}

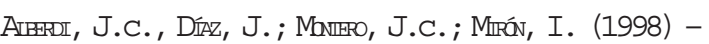
"Daily mortality in Madrid Commity (Spain) 1986-1991: Relationship with atmospheric variables" . European Joumal of Epidemiology, 14:571-578.

Alcoforado, Maria J. ; Nunes, M. Fátima; Garcia, Ricardo (1999) - "A percepp̧ão da relação climasaúde pública em Lisboca, no século XIX, através da obra de Marino Miguel Franzini" . Revista Portuguesa de Saúde Püblica, 17 (2) :31-40.

ArcofcRado, Maria J. (2000) - "Riscos Climáticos" . Actas do Colóquio "Geografia dos Riscos. Universidade de Lisboa, CEG, Lisboa, 31-45.

Imerican Meteorological Society (AMS) (2000) - Glossary of Meteorology, AmericanMeteorological Society, in http: //amsglossary.allenpress.com/glossary/ prefacel, acedido 17/10/2008.

AndRADE, Henrique (2003) - Bioclima Humano e Temperatura do Ar em Lisboa. Tese de Doutoramento, apresesentada à Faculdade de Letras da Universidade de Lisboa.

Anunes, Sílvia; Pires, Henrique O.; Roch, Alfredo (2001) - "Improvement of prediction using SSA methods in addition to MEM: Case of NAO study" . 8th International Meeting on Statistical Climatology, GKSS, Luneburg, Alemanha.

Bates, B.C. ; Kundzantcz, Z.W. ; Wu, S. ; Pauntikof, J.P. (2008) - Climate Change and Water. Technical Paper of the Intergovernmental Panel an Climate Change, IPCC Secretariat, Geneva, 210 p.

Bensav, Keith; Kocasu, Patricia; Strrme, James (2000) - "Climate change and health in the Mid-Atlantic Region". Climate Research, 14:245-253.

CAIPRIN, Judite (2000, 2001 e 2002) - Risco de Mbrrer em Portugal. DSIA, Divisão de Epidemiologia. Direcção-Geral da Saúde. Lisboa. 232 p.

CGER. Commission on Geosciences, Enviroment and Resources (2001) - Under the Weather: Climate, Ecasystems, and Infectious Disease, Atmospheric 
Sciences and climate. Division on Earth and Life Studies, National Academy of Sciences, Washington, D.C.

CtrRIHRO, F.C. ; HEINER, K.S. ; SAMET, J. M. ; ZRER, S. L. ; Stru, L. ; PAlZ, J. A. (2002) - "Temperature and mortality in 11 cities of the Eastem United States" . American Joumal of Epidemiology, 155 (1) : 80-87.

DAVEAU, Suzanne (1995) - Portugal Geográfico. Edições João Sá da Costa, Lisbooa, $4^{2}$ edição 2005, 223 p.

Davis, Robert E. ; KNAPPEnberger, Paul C. ; Michaets, Patrick J. ; Nvvicorf, Wendy M. (2002) - Changing Heat Wave Mortality in U.S. cities. http:// ams. confex. com/ams/pdfpapers/69575.pdf , acedido 17/9/2007.

DEssi, Straje (2003) - "Heat stress and mortality in Lisbon, Part II. An Assessment of the potential impacts of climate change". Intemational Jamal of Biometeorology, 48:37-44.

Dissai, Suraje (2004) - Probabilities, climate change scenarios and adaptation decision-making. http: / /www.uea.ac.uk/ e120782/phoupdate04 .pdf, acedido 17/9/2007.

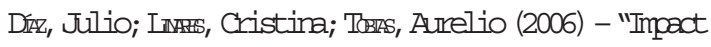
of extreme temperatures on daily mortality inMedrid (Spain) among the 45-65 age-group". Intemational Jamal Biameteorology, 50:342-348.

Daninon, G. C. ; Kertine, W. R. (2002) - "Excess winter mortality: influenza or cold stress? Observatory study". BritishMedical Jamal, 324:89-90.

FALc̃̃o, José M. ; CAstro, M.J. ; Fàcão, J. P. (1988) "Efeitos de uma onda de calor na mortalidade da população do distrito de Lisboa" . Saúde em Nímeros, 3 (2) :9-12.

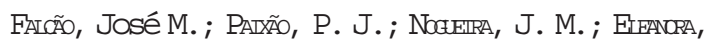
J. P. (2004) - Efeitos do frio nas famílias portuguesas. Observatório Nacional de Saúde Estudo na amostra Ecos.

Gran, A. S. ; Burr, A. B. G. ; Shontr-TOMIC, K. E. (2001) - "Dengue epidemics and El Niño Southern Oscillation". Climate Research, 19:35-43.

GARCIA, A. C. ; NoGHEIRA, M. J. ; FALCÃO, J. M. (1999) "Onda de calor de Junho de 1981 em Portugal: efeitos na mortalidade". Revista Portuguesa de Saúde Püblica. Volume temático: 1.

Gavel, Islay; McIone, Philip; Bowr, F. A. ; Diaknson, Gordon J. ; WATT, G. C. M. (2002) - "Seasonal variation inmortality in Scotland". Intemational Joumal of Epidemiology. 29 (2) :274-279.

INE (2007) - Estatísticas Demográficas e Sociais. Iiscoa.

IPCC (2001) - Climate change 2001: The Scientific Basis. http: //www.grida.no/publications/other/ ipcc_tar/?src=/climate/ipcc_tar/wgl/ index.htm. acedido em 20/03/2008.
KaIKESIEIN, Laurence S. (1991) - "A New Approach to Evaluate the Impact of Climate on Hum Mbrtality" . Enviramental Health Perspectives, 96:145-150.

KAIKESIEIN, Laurence S. ; GRFHN, J. S. (1997) - "An evaluation of climate/mortality relationships in large U.S. cities and the possible impacts of a climate change". Environmental Health Perspectives. 105:84-93.

Kourras, Korine N. ; Covre, A. C. (2004) - "Climate and infectiaus disease in the sathrestem Hited States". Progress in Physical Geography. 28:387-398.

Mackenbach, J. P. ; Kinst, A. E. ; Lonan, C. W. N. (1992) - "Seasonal variation in mortality in the Netherlands". Journal of Epidemiology and Commmity Health. 46: 261-265.

Maroues, Jorge (2007) - Condições climáticas de Inverno e a mortalidade diária no distrito de Lisboa. Tese de mestrado, apresentada à Faculdade de Letras da Universidade de Lisboa.

MhIZARAKIS, Andreas; MyYrR, H. (1991) - "The extreme heat wave in Athens in Jily 1987 from the point of view of Human Biometeorology" . Atmospheric Erviroment 25B, 203-211.

Mcree, M. ; SAnderson, C. ; Chennet, L. ; VAssin, S. ; SHrornko, V. (1998) - "Seasonal variation in mortality in Mascow". Joumal of Public Health. 20 (3) :268-274.

NogteIRA, Paulo; PAIX̃̃o, Eleonora; Rotrigues, Emanuel (2007) - Sazonalidade e Periodicidades da Mortalidade Portuguesa - 1980 a 2001 . Fundação Merck Sharp \& Dohme, Lisboa, 268 pp.

PEixo10, Jasé Pinto. (1987) - O sistema climático e as bases físicas do clima. Secretaria de Estado do Ambiente e dos Recursos Naturais.

Pando, José Pinto; Cort, A. H. (1992) - Physics of Clinate. American Institute of Physics, New Yodk, 520 p.

Pinteiro, Carlos (1990) - "Um frio de morrer ou a variação da mortalidade e cl ima nos distritos de Viana do Castelo e de Fard" . Arquivos do Instituto Nacional de Saúde, 15:61-112.

PIAT, G. ; VEMRA, R. (1994) - "Spellls of low-frequency oscillations and weather regimes in the northem hemisphere". Joumal of the Atmospheric Sciences, 51-2: 210-236.

PNAAS (2008) - Plano Nacional de Acção Ambiente e Saúde.

Rarictes, Bento (1978) - "Considerações a propósito da variação estacional da mortalidade por doenças-vasculares, em Portugal". Revista Portuguesa de Clínica e Terâpeutica, 4 (3) :97-104) .

SACARR̃̃o, G. F. (1981) - A temperatura como factor ecológico. Secretaria de Estado do Urbanismo e Ambiente. Comissão Nacional do Ambiente, 184 pp. .

Santana, Paula; VAz, A.; FAchadA, M. (2004) - "O estado de saúde dos Portugueses. Uma 
perspectiva espacial" . Revista de Estudos Demográficos, n. ${ }^{\circ} 36, \mathbb{N E}$, Lisboa.

SAnOS, Filipe D. ; Forts, K. ; Mbra, R. (2002) - Climate Change in Portugal Scenarios, Impacts and Adaptation Measures. SIAM PROJECT. Editora Gradiva, Lisboa.

Sannos, Filipe D.; Miranda, Pedro (eds.) (2006) - O Clima de Portugal nos séaulos XX eXXI, Alterações climáticas em Portugal. Cenários Impactos e medidas de Adaptação. Projecto SIAM II, 47-113 pp. Gradiva. Iisboa.

Tharrus, J. D. ; Wiss, E. K. ; UвHO, C. K. ; Necor, A. L. ; Covrs, A. C. (2007) - "Climate and human health: synthesizing environmental complexity and uncertainty". Stochastic Enviromental Research and Risk Assessment. Springer-Verlag. 21 (5) :601613.

VAUIAR, R. ; YIor, P. ; Gru, M. (1992) - "Singular spectnmanalysis: A toolkit for short, noisy dactic signals". Physica D. (58) : 95-126.

Wilkinsan, P.; Pattenden, S. ; Arnstrang, B.; Fletcher, A. ; Kovats, R. S.; ManGTANI, P.; MCMiaraed, A. J. (2004) - "Vulnerability to winter mortality in elderly peqple in Britain: population based study" . BritishMedical Joumal, (329) :647-653. 